\title{
The Evolving Role of Retail Clinics
}

$\mathrm{R}$

etail clinics are medical clinics located in pharmacies, grocery stores, and "big box" stores, such as Target and

Walmart. These clinics offer extended weekend and evening hours, walk-in availability, and short wait times. Many visits to retail clinics are in the evenings and weekends, when primary care offices are not available. The clinics treat a limited range of health conditions, such as minor infections and injuries, and provide vaccines and other preventive care. Care is delivered by a nurse practitioner or physician assistant. Prices are typically fixed and transparent.

Retail clinics have been proposed as an alternative to costly emergency department care for nonemergency conditions. It has been estimated that up to 20 percent of emergency department visits for a nonemergency condition could take place at a retail clinic or urgent care center, potentially generating cost savings as high as $\$ 4.4$ billion annually.

Retail clinics are playing a steadily growing role in the health care marketplace. The first retail clinics opened in 2000; by 2010, they numbered close to 1,200. Recent estimates predict that there will be more than 2,800 clinics by 2017, nearly double the 2014 levels. Convenience, accessibility after hours, and clear pricing appear to be the most important drivers of growth. Consumers are relatively happy with their overall care experiences.

But retail clinics have also generated controversy. Provider groups, such as the American Medical Association, have raised concerns about quality-of-care issues, including the overprescribing of antibiotics, lost opportunities for preventive care, and the disruption of existing patient-physician relationships. Conversely, champions of the retail clinic model have pointed to their potential benefits: Retail clinics may function as a provider for lower-income patients and those without a primary care physician and could also provide a less costly alternative for patients who otherwise would go to emergency departments. By replacing more expensive emergency department visits, the hope is that retail clinics may decrease health care spending.

To provide a factual basis for assessing retail clinics, RAND Health researchers conducted a series of studies focusing on four areas:

- A profile of retail clinics: Where are retail clinics located, what services do they offer, and who owns them?

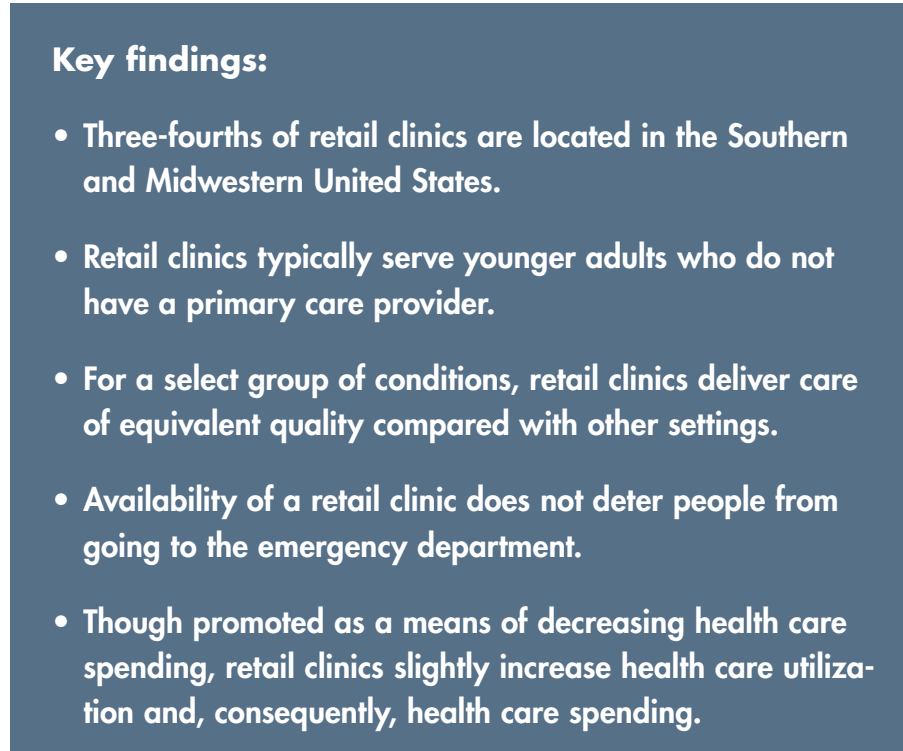

- Patient characteristics and service use: Who uses retail clinics, and what services do patients obtain?

- Quality and delivery of preventive care: How do retail clinics compare on these dimensions with other health care settings?

- Costs: How do retail clinic costs compare with the cost of services in a physician's office or in an emergency department? Are there potential savings if retail clinic visits can substitute for more expensive care in other venues?

\section{Most Retail Clinics Operate in the Southern and Midwestern United States in Large Metropolitan Areas}

RAND analysis of 2014 data shows that the vast majority (74 percent) of the 2,737 retail clinics in the nation were located in the South and Midwest (Figure 1). More than a third of all clinics were located in five states (California, Florida, Illinois, Minnesota, and Texas).

These results largely echo prior RAND research on retail clinic locations. That work used cross-sectional data from industry and foundation sources to analyze the characteristics of 982 retail clinics operating in the United States (as of August 2008). RAND's analyses revealed the following findings. 
Figure 1. U.S. Retail Clinics Are Concentrated in the Southern and Midwestern United States

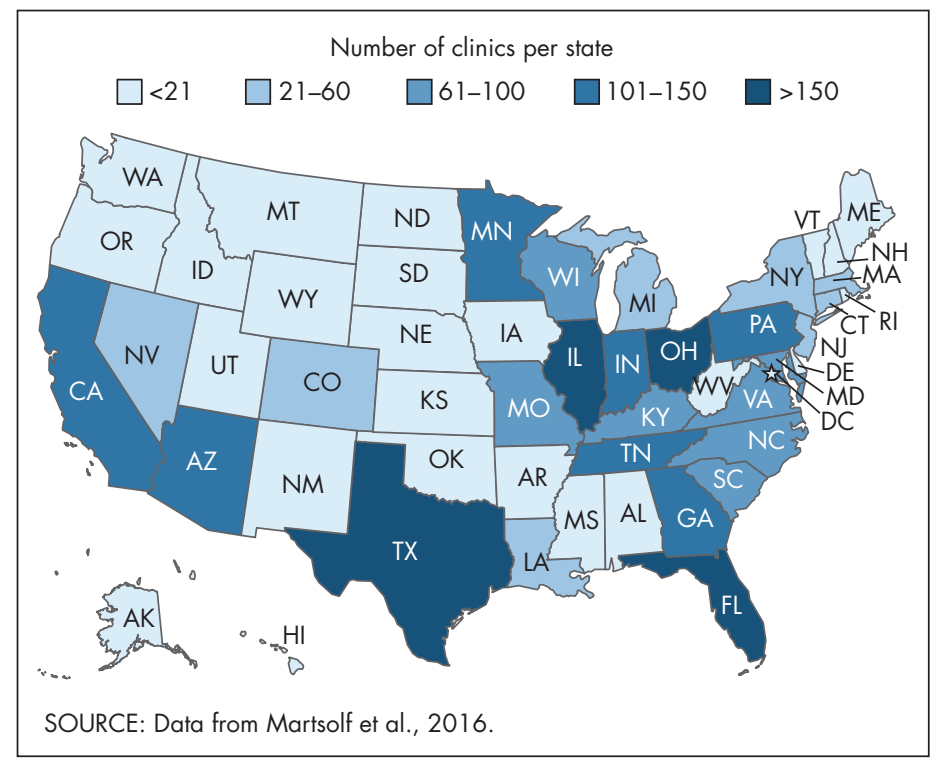

\section{Geographic Distribution}

- About 35 percent of the U.S. urban population lived within a ten-minute driving distance of a retail clinic.

- Retail clinics tended to be located in higher-income urban and suburban settings, with higher concentrations of white residents and fewer black and Hispanic residents. Only 12.5 percent were located in medically underserved areas. For comparison, 21 percent of the U.S. population lives in such areas. Even after adjusting for the location of pharmacies and supermarket chains, clinics were less likely to be located in medically underserved neighborhoods than in other areas.

\section{Services}

- Clinics offered treatment for a limited set of conditions for which they had treatment protocols, including acute respiratory infections-which accounted for 60 percent of all retail clinic visits-other minor illnesses, immunizations, sports physicals, and screening services, such as lipid or diabetes screening.

- The majority of retail clinics accepted commercial, Medicare, and Medicaid coverage, and all accepted cash payment, regardless of insurance status.

\section{Ownership}

- Two organizations-CVS and Walgreens-operated about three-quarters of all retail clinics.

- Adding clinics operated by Kroger, Walmart, Target, and RiteAid accounted for 93 percent of retail clinics nationwide. Note that, as of 2016, Target's clinics are operated by CVS.

\section{Typical Retail Clinic Patients Are Younger Adults with No Regular Provider}

Who uses retail clinics, and why? RAND researchers analyzed details of more than 1.3 million visits to retail clinics from 2000 to 2007 and compared information from that analysis with national data on visits to primary care physician offices and emergency departments. According to the study's findings: The largest group of clinic users was young adults, age 18-44, who accounted for 43 percent of patients. Nationally, this group made up only 23 percent of patients who visited primary care physicians.

- Only about one-third of clinic users said that they had a primary care physician.

- Two-thirds of retail clinic visits were paid for with health insurance, compared with 90 percent of visits to primary care physicians.

- About 90 percent of visits to retail clinics were for preventive care and for ten simple acute conditions: upper respiratory infections, sinusitis, bronchitis, sore throat, immunizations, inner ear infections, swimmer's ear, conjunctivitis, urinary tract infections, and blood tests. The same conditions accounted for 18 percent of visits to primary care physician offices and 12 percent of emergency department visits.

\section{Retail Clinics Offer Comparable Quality of Care for Some Medical Conditions}

Critics of retail clinics are concerned that they offer substandard care and that using a retail clinic disrupts patientphysician relationships. The evidence suggests otherwise:

- Quality of care: RAND analysts evaluated claims data from enrollees in a large Minnesota health plan who received care for one of three common conditions: otitis media (inflammation of the middle ear), pharyngitis (sore throat), or urinary tract infection. Based on 12 quality-of-care measures, retail clinics, physician offices, and urgent care centers had similar quality ratings; quality scores were lower for emergency departments.

- Antibiotic prescribing: Acute respiratory infections, such as bronchitis and rhinosinusitis, are the most common reason that patients seek care in the United States and account for 60 percent of all retail clinic visits. Physicians often overprescribe antibiotics for these conditions, and experts were concerned that overprescribing would be even more frequent in retail clinics. The research did not support this concern. Using data from the medical records of physician offices, retail clinics, and emergency departments, researchers found that the share of patients who were prescribed antibiotics was similar for retail clinics, physician offices, and emergency departments. In fact, care at 
retail clinics was more guideline-concordant. For such conditions as bronchitis, for which antibiotics are never indicated, retail clinics had a lower antibiotic prescribing rate than physician offices.

- Vaccinations: Retail clinics have been viewed as a promising venue for administering vaccinations. A study examined how many vaccinations were delivered at the largest retail clinic chains from 2007 through 2009, what percentage of clinic visits included vaccinations, and which vaccinations were the most common. In the time period studied, vaccinations were administered in about 40 percent of visits; the most common vaccination was for influenza.

- Those receiving vaccinations were typically not "outside the medical system" but instead may have chosen to receive a vaccination at the retail clinic because it was more convenient than the doctor's office. Retail clinics could deliver more vaccinations if they counseled patients during acute care visits about the benefits of vaccinations.

- Continuity of care: Some physician groups have expressed concerns that using retail clinics will disrupt existing patient-physician relationships. However, multiple studies have found that the majority of retail clinic patients report not having a primary care provider. Retail clinics seem to be serving a population that does not seek care in a doctor's office but might otherwise seek care in emergency departments. Retail clinics might reduce the likelihood that a patient will go to a primary care physician first for a new condition and decrease subsequent continuity of care. However, patients who visit retail clinics appear just as likely to receive preventive care or proper management of diabetes.

\section{Retail Clinics Increase Both Health Care Use and Health Care Spending}

Policymakers and insurers have viewed retail clinics as a way to decrease health care spending: Less expensive care for low-acuity conditions, such as bronchitis and urinary tract infections, in a retail clinic could substitute for more expensive care in a physician's office or an emergency department. However, RAND research has not supported this idea. A recent study compared emergency departments with a retail clinic nearby to emergency departments with no retail clinic nearby. There was no notable reduction in visits for minor conditions to the emergency departments in close proximity to retail clinics.

More broadly, the key to cost savings from retail clinics is substitution. Retail clinics generate cost savings only if less expensive clinic visits substitute for more costly care from physicians or emergency departments. On the other hand, retail clinic visits could also increase costs if they generate new health care use by patients seeking care when they otherwise would have stayed home. To gauge substitution versus new utilization, RAND followed two groups of enrollees-users and nonusers of retail clinics-among 1.3 million Aetna enrollees in 22 cities in 2010 and 2011. The groups had similar low-acuity conditions.

Researchers found that about two-fifths of retail clinic visits for these conditions were substitutions for physician office or emergency department visits. The other three-fifths of clinic visits reflected new utilization, not substitution (see Figure 2). Given that retail clinics focus on making it easy to access care, it is not surprising that some individuals who might have done nothing about their condition sought care for it because it was convenient.

The costs of the new health care utilization more than offset the savings from substitution (Figure 2). There was a relatively small net increase in patient spending ( $\$ 14$ per person per year). Many payers are including retail clinics in their provider networks and encouraging enrollees to use them.

To the extent that the provider's goal is to reduce health care spending, encouraging retail clinic use might not be effective.

\section{Summary and Implications}

RAND's body of work substantially strengthened understanding of the patients served by retail clinics, the quality of the care that those patients receive, and the clinics' net cost effects:

- Younger adults and those without a regular care provider are typical users of retail clinics.

- Overall, retail clinics are not improving access to care for the medically underserved; retail clinics are more likely

\section{Figure 2. Increased Utilization in Health Care Clinics Partially Offsets Savings}

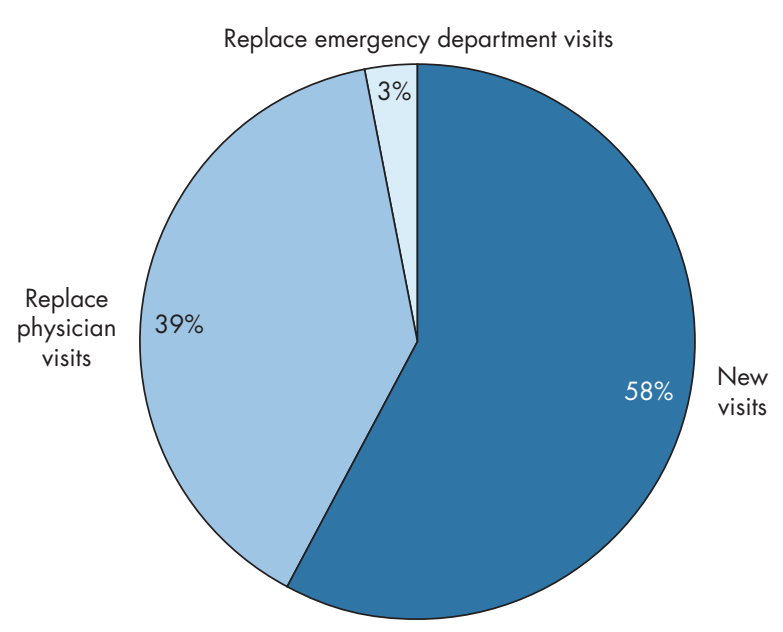

SOURCE: Ashwood et al., 2016. 
to be located in relatively affluent sections of large urban areas.

- Retail clinics provide care that is of equivalent quality to the care provided by physician offices and emergency departments.

- Retail clinics have not led to any substantive decline in emergency department visits.
- More than half of clinic visits for low-acuity conditions represented new health care utilization. As a result, contrary to expectations, retail clinics increased health care spending per person per year.

\section{This research highlight summarizes RAND Health research reported in the following publications:}

Ashwood JS, Gaynor M, Setodji CM, Reid RO, Weber E, and Mehrotra A, "Retail Clinic Visits for Low-Acuity Conditions Increase Utilization and Spending," Health Affairs, Vol. 35, No. 3, March 2016, pp. 449-455 (EP-66379, www.rand.org/t/) EP66379).

Ashwood JS, Reid RO, Setodji CM, Weber E, Gaynor M, and Mehrotra A, "Trends in Retail Clinic Use Among the Commercially Insured," American Journal of Managed Care, Vol. 17, No. 11, November 2011, pp. e443-e448 (EP-201100-245, www.rand.org/t/EP201100245).

Martsolf G, Fingar KR, Coffey RM, Kandrack R, Charland T, Eibner C, Elixhauser A, Steiner C, and Mehrotra A, "Association Between the Opening of Retail Clinics and Low-Acuity Emergency Department Visits," Annals of Emergency Medicine, November 2016.

Mehrotra A, Gidengil CA, Setodji CM, Burns RM, and Linder JA, "Antibiotic Prescribing for Respiratory Infections at Retail Clinics, Physician Practices, and Emergency Departments," American Journal of Managed Care, Vol. 21, No. 4, April 2015, pp. 294-302.

Mehrotra A and Lave JR, "Visits to Retail Clinics Grew Fourfold from 2007 to 2009, Although Their Share of Overall Outpatient Visits Remains Low," Health Affairs, Vol. 31, No. 9, September 2012, pp. 2123-2129 (EP-51022, www.rand.org/t/EP51022).

Mehrotra A, Liu H, Adams JL, Wang MC, Lave JR, Thygeson NM, Solberg LI, and McGlynn EA, "Comparing Costs and Quality of Care at Retail Clinics with That of Other Medical Settings for 3 Common Illnesses," Annals of Internal Medicine, Vol. 151, No. 5, September 2009, pp. 321-328 (EP-200909-15, www.rand.org/t/ EP20090915).

Mehrotra A, Wang MC, Lave JR, Adams JL, and McGlynn EA, "Retail Clinics, Primary Care Physicians, and Emergency Departments: A Comparison of Patients' Visits," Health Affairs, Vol. 27, No. 5, September/October 2008, pp. 1272-1282 (EP-200809-13, www.rand.org/t/EP20080913).

Pollack CE, Gidengil C, and Mehrotra A, "The Growth of Retail Clinics and the Medical Home: Two Trends in Concert or in Conflict?" Health Affairs, Vol. 29, No. 5, May 2010, pp. 998-1003 (EP-201000-29, www.rand.org/t/EP20100029).
Reid RO, Ashwood JS, Friedberg MW, Weber ES, Setodji CM, and Mehrotra A, "Retail Clinic Visits and Receipt of Primary Care," Journal of General Internal Medicine, Vol. 28, No. 4, April 2013a, pp. 504-512 (EP-51146, www.rand.org/t/) EP51146).

Reid RO and Mehrotra A, "Primary Care Practice Response to Retail Clinics," AMA Journal of Ethics, Vol. 15, No. 11, November 2013b, pp. 937-942.

Rudavsky R and Mehrotra A, "Sociodemographic Characteristics of Communities Served by Retail Clinics," Journal of the American Board of Family Medicine, Vol. 23, No. 1, January/February 2010, pp. 42-48 (EP-201000-03, www.rand.org/t/ EP20100003).

Rudavsky R, Pollack CE, and Mehrotra A, "The Geographic Distribution, Ownership, Prices, and Scope of Practice at Retail Clinics," Annals of Internal Medicine, Vol. 151, No. 5, September 1, 2009, pp. 315-320, W-103-W-108 (EP-200909-13, www.rand.org/t/EP20090913).

Uscher-Pines L, Harris KM, Burns RM, and Mehrotra A, "The Growth of Retail Clinics in Vaccination Delivery in the U.S.," American Journal of Preventive Medicine, Vol. 43, No. 1, July 2012, pp. 63-66 (EP-201200-163, www.rand.org/t/EP201200163).

Wang MC, Ryan G, McGlynn EA, and Mehrotra A, "Why Do Patients Seek Care at Retail Clinics, and What Alternatives Did They Consider?" American Journal of Medical Quality, Vol. 25, No. 2, March/April 2010, pp. 128-134 (EP-201000-02, www.rand.org/t/EP20100002).

Weinick RM, Burns RM, and Mehrotra A, "Many Emergency Department Visits Could Be Managed at Urgent Care Centers and Retail Clinics," Health Affairs, Vol. 29, No. 9, September 2010, pp. 1630-1636 (EP-201001-23, www.rand.org/t/ EP20100123).

Weinick RM, Pollack CE, Fisher PF, Gillen EM, and Mehrotra A, Policy Implications of the Use of Retail Clinics, Santa Monica, Calif.: RAND Corporation, TR-810-DHHS, 2010 (www.rand.org/t/TR810).

\footnotetext{
Abstracts of all RAND Health publications and full text of many research documents can be found on the RAND Health website at www.rand.org/health. To view this brief online, visit www.rand.org/t/RB9491-2. The RAND Corporation is a research organization that develops solutions to public policy challenges to help make communities throughout the world safer and more secure, healthier and more prosperous. RAND is nonprofit, nonpartisan, and committed to the public interest. RAND's publications do not necessarily reflect the opinions of its research clients and sponsors. RAND ${ }^{\circledR}$ is a registered trademark. ๑ RAND 2016

Limited Print and Electronic Distribution Rights: This document and trademark(s) contained herein are protected by law. This representation of RAND intellectual property is provided for noncommercial use only. Unauthorized posting of this publication online is prohibited. Permission is given to duplicate this document for personal use only, as long as it is unaltered and complete. Permission is required from RAND to reproduce, or reuse in another form, any of our research documents for commercial use. For information on reprint and linking permissions, please visit www.rand.org/pubs/permissions.
} 